\title{
Low Cost Equipment and Short Duration Program Are Not Barriers to Good Outcomes of Cardiac Rehabilitation in Senegalese Patients with Coronary Artery Disease
}

\author{
Mame Madjiguène Ka*, Waly Niang Mboup, Serigne Cheikh Tidiane Ndao, \\ Sènankpon Paterne Aymard Abadassi, Djibril Marie Ba, Khadidiatou Dia, \\ Pape Diadie Fall, Mouhamed Chérif Mboup
}

Hôpital Principal de Dakar, Dakar, Senegal

Email: ^madjigueneka@gmail.com

How to cite this paper: Ka, M.M., Mboup, W.N., Ndao, S.C.T., Abadassi, S.P.A., Ba, D.M., Dia, K., Fall, P.D. and Mboup, M.C. (2021) Low Cost Equipment and Short Duration Program Are Not Barriers to Good Outcomes of Cardiac Rehabilitation in Senegalese Patients with Coronary Artery Disease. World Journal of Cardiovascular Diseases, 11, 421-433.

https://doi.org/10.4236/wjcd.2021.119039

Received: August 7, 2021

Accepted: September 6, 2021

Published: September 9, 2021

Copyright $\odot 2021$ by author(s) and Scientific Research Publishing Inc. This work is licensed under the Creative Commons Attribution International License (CC BY 4.0).

http://creativecommons.org/licenses/by/4.0/

\begin{abstract}
Cardiac rehabilitation is still underused in Africa, despite its cost effectiveness widely demonstrated around the world. Aim: To evaluate the results of a cardiac rehabilitation program in the first Senegalese outpatient center in low resource context. Patients and Method: We carried out a prospective and interventional study. It compared on one hand a group of coronary patients at baseline and after 6 months of our rehabilitation program and on the other hand a control group of patients not enrolled in rehabilitation. Results: We included 70 patients (30 in the rehabilitation group and 40 in the control group). After rehabilitation, the functional capacity improved: $6.99 \pm 2.9$ Mets at M0 vs $8.8 \pm 2.23$ Mets at M6, p $=0.0001$. Patients of intervention group significantly increased motivation to lifestyle changes and knowledge about their disease. We found better control at 6 months of hypertension (84.50\% vs $33.70 \%, p=0.003)$, diabetes $(70.00 \%$ vs $26.70 \%, p=0.0042)$, LDL cholesterol $(33.00 \%$ vs $5.00 \%, \mathrm{p}=0.002)$ in the group "Rehabilitation". Prevalence of psychosocial issues like anxiety and depression decreased in intervention group: $50.00 \%$ at $\mathrm{M} 0$ to $23.33 \%$ at $\mathrm{M} 3$ ( $\mathrm{p}=0.021$ ), then $30.00 \%$ at M6 $(\mathrm{p}=0.18)$. Return to work and resuming sexual activity were not significantly different. Conclusion: Comprehensive cardiac rehabilitation program, with low cost equipment in a short duration, could have real benefits in the management of coronary artery disease by reducing anxiety and depression, improving treatment compliance, control of cardiovascular risk factors, lifestyle changes and disease knowledge.
\end{abstract}




\section{Keywords}

Cardiac Rehabilitation, Patient Education, Cardiovascular Risks Factors, Psychosocial Factors, Coronary Artery Disease, Africa

\section{Introduction}

Cardiovascular rehabilitation is nowadays a cornerstone of secondary prevention in the management of coronary artery disease [1]. Indeed, participation in a cardiac rehabilitation program has been correlated with a better quality of life as well as a decrease in morbidity and mortality associated with cardiovascular disease [2]. This intervention is a multicomponent and complex model of care. Consequently, the nature and the quality of services may vary significantly around the globe, according to the country's income, the available professionals and other factors [3].

In sub-Saharan Africa, numerous technical progresses, interventional or surgical, are being made to reduce the burden of coronary artery disease. But cardiac rehabilitation remains almost non-existent in this area of the world. Very few African data are available on the impact of cardiac rehabilitation [4] [5] [6]. This fact could be due to several barriers identified in low- and middle-income countries such as socio-economic factors [4].

The aim of this work was to evaluate the results of a short cardiac rehabilitation program, performed by the first Senegalese outpatient center.

\section{Methods}

\subsection{Patients and Study Setting}

This is a prospective, interventional, case-control type study concerning two groups of patients followed for coronary heart disease, in the cardiology departments of two level 3 hospitals in Dakar (Senegal) from February 2019 to October 2019. In the "case" group, patients are referred to the cardiac rehabilitation unit, after an initial hospitalization for acute or chronic coronary syndrome. The patients of the control group had regular outpatient visits after hospitalization. They were self-selected. Counselling for the risk factors management was provided during the medical visit. Their data were collected at the beginning and the end of the follow-up.

The patients who were not included in our study were those:

- Unable to participate in the study due to their geographical location

- Not having had at least semi-annual follow-ups

- Whose files were unusable

- Not wanting to participate in the study

\subsection{General Organization of the Rehabilitation Program}

The team is made up of a cardiologist specialized in cardiac rehabilitation, a di- 
abetologist, a dietitian-nutritionist, two physiotherapists, a nurse, a nurse aide and a sports instructor. A psychologist is called upon if necessary. First, an initial interview is made by the nurse or nurse aide. This interview assesses the patient's psychological, social and professional environment, his habits and life plans, his expectations regarding the program.

\subsection{Training}

Training takes place in a dedicated room, equipped with an emergency trolley (including semi-automatic defibrillator), programmable bicycles ergometers and treadmills for domestic use, and various gym equipment. The accommodation capacity is 24 patients per day. Patients get an average of 15 to 20 sessions of exercise 3 times a week. The number of prescribed training sessions varies according to the indication, age, comorbidities, initial functional capacity and the goals negotiated during the educational diagnosis.

A non-compulsory exercise test is carried out at the end of the program in order to gauge the improvement in the patient's physical capacities, to determine the limits of training during phase 3 post-rehabilitation and above all, to propose an adjustment or a change of workstation when needed.

\subsection{Patient Education}

The monthly patient education program includes collective sessions on general topics (cardiovascular system functioning, cardiovascular risk factors, blood pressure, blood sugar and carbohydrate metabolism disorders, food families, etc.) intended for all patients. There are also specific topics (coronary disease, heart failure, hypertension, diabetes, anticoagulants) reserved for individuals with these pathologies. The individual sessions concern special cases such as the existence of a language barrier, or a special diet. At the beginning and end of a monthly therapeutic education program, a knowledge and motivation assessment questionnaire is completed for each patient.

\subsection{Ethical Aspects}

Inclusion in our study was conditional on obtaining informed consent from patients. Anonymity and confidentiality were respected throughout our study.

\subsection{Data Collection and Statistical Analysis}

We assessed adherence to the rehabilitation program as well as attendance:

1) Adherence: were considered adherents, the patients enrolled having performed at least one of the prescribed sessions [7] [8];

2) Attendance: were considered assiduous, the patients registered having performed at least $67 \%$ of the prescribed sessions [9].

The data was collected from medical visit or rehabilitation files. The missing information was completed during a visit or by phone call. We explored:

1) Anamnestic data: age, gender, professional situation, medical and surgical 
history, cardiovascular risk factors, indications for rehabilitation, functional signs;

2) Clinical elements: blood pressure (BP), heart rate (HR), respiratory rate (FR), waist circumference, abnormalities of the clinical examination;

3) Paraclinical data: biological assessment (blood count, fasting blood sugar, total/HDL/LDL cholesterol, triglycerides, uricemia, blood ionogram, urea, creatinine, glycated hemoglobin for diabetics);

4) Parameters at 6 months after rehabilitation: therapeutic compliance, regular physical activity practice (at least 30 minutes at moderate intensity three times a week) and cardioprotective diet (low saturated fats, low carbs, high fibers, fruits and vegetables) after rehabilitation period by a questionnaire; control of CVRF; increase of ischemic threshold; outcomes of disease in psychosocial terms (by Hospital Anxiety and Depression Scale > 10) [10], in professional activities and in sexual activity.

The therapeutic targets of diabetes $(\mathrm{HbAlC}<7 \%)$, arterial hypertension $(\mathrm{BP}<$ $140 / 90 \mathrm{mmHg})$ and LDL cholesterol $(<70 \mathrm{mg} / \mathrm{dL})$ have been defined according to the recommendations of the ESC of 2016 in the prevention of cardiovascular diseases [11].

Treatment compliance was assessed using a questionnaire established by Girerd X et al. [12] allowing classification into three groups: complete compliance, partial compliance, non-compliance.

Data analysis was performed with Statistical Package for the Social Sciences (SPSS) version 18 software. The various parameters collected are analyzed using Chi-square tests, Pearson, Fisher's two-tailed exact test or Student's test according to their conditions of applicability. The quantitative parameters were expressed as means \pm standard deviation. The comparison of the means was made with the analysis of variance test for the independent data and by the Student's test for the linked data. The various statistical tests used were considered significant for a $\mathrm{p}$ value $<0.05$.

\section{Results}

\subsection{Characteristics of the Study Population}

Seventy (70) patients were included in our study: 30 in the "rehabilitation" group who were enrolled in the outpatient cardiovascular rehabilitation program and 40 in the "no-rehabilitation" group followed on an outpatient basis for coronary artery disease.

During the study period, 62 patients were enrolled in the cardiovascular rehabilitation unit with an indication of coronary artery disease. Among them, 48 completed at least one session of the program, which makes the adherence rate $77.41 \%$. The attendance rate was estimated at $70.96 \%(n=44)$. Barriers to the participation or completion of rehabilitation were: socio-economic factors such as lack of medical insurance, low level of education and low income; professional and social constraints; living far from the center. Of the 44 attending patients, 14 
did not come to the sixth-month check-up.

The mean age was $61.01 \pm 10.6$ years [36 to 84 years]. The most represented age group was that of 60 years and over who represented $46.70 \%(n=14)$ of patients in the rehabilitation group and $57.50 \%(\mathrm{n}=23)$ of controls. The most common CVRF were dyslipidemia, sedentary lifestyle, overweight and high blood pressure. Table 1 summarizes the characteristics of our study population.

\subsection{Rehabilitation Indications}

Fifty-three patients $(75.70 \%)$ were included in our study after acute coronary syndrome (ACS) and 17 (24.30\%) were followed for chronic coronary syndrome (CCS). Half of the patients (50.00\%) of the rehabilitated patients are followed for CCS. Thirty-five patients $(50.00 \%)$ in our study population had undergone myocardial revascularization. Among them, 27 were in the rehabilitation group (21 percutaneous coronary interventions, 06 bypass surgery, 01 hybrid procedure) and 08 (08 percutaneous coronary interventions) in the non-rehabilitated group.

Table 1. Characteristics of study population.

\begin{tabular}{|c|c|c|c|c|}
\hline Data & Rehabilitation & No rehabilitation & Total & $\mathrm{p}$ \\
\hline \multicolumn{5}{|c|}{ Socio-demographic characteristics } \\
\hline Mean age $($ years $)$ & $59.90 \pm 10.71$ & $61.85 \pm 10.56$ & $61.01 \pm 10.60$ & 0.45 \\
\hline Men & $21(70.0 \%)$ & $26(65.0 \%)$ & $47(67.1 \%)$ & \\
\hline & & & & 0.66 \\
\hline Women & $9(30.0 \%)$ & $14(35.0 \%)$ & $23(32.9 \%)$ & \\
\hline Postgraduate level & $25(83.3 \%)$ & $32(80.0 \%)$ & $57(81.4 \%)$ & 0.72 \\
\hline Married & $30(100.0 \%)$ & $35(87.5 \%)$ & $65(92.9 \%)$ & 0.05 \\
\hline Medical insurance & $29(96.7 \%)$ & $22(55.0 \%)$ & $51(72.9 \%)$ & 0.00 \\
\hline Professional activity & $23(76.7 \%)$ & $18(45.0 \%)$ & $41(58.6 \%)$ & 0.01 \\
\hline \multicolumn{5}{|c|}{ Clinical characteristics } \\
\hline Diabetes mellitus & $10(33.30 \%)$ & $15(37.50 \%)$ & $25(35.70 \%)$ & 0.72 \\
\hline Dyslipidemia & $20(66.70 \%)$ & $28(70.00 \%)$ & $48(68.60 \%)$ & 0.77 \\
\hline Sedentary lifestyle & $17(56.70 \%)$ & $34(85.00 \%)$ & $51(72.90 \%)$ & 0.01 \\
\hline Hypertension & $13(43.30 \%)$ & $24(60.00 \%)$ & $37(52.90 \%)$ & 0.17 \\
\hline Tobacco use & $12(40 \%)$ & $11(27.5 \%)$ & $23(32.9 \%)$ & 0.271 \\
\hline Stress & $20(66.70 \%)$ & $3(7.5 \%)$ & $23(32.86 \%)$ & 0.0001 \\
\hline Coronary heredity & $3(10 \%)$ & $0(0 \%)$ & $3(4.49 \%)$ & 0.007 \\
\hline Obesity and overweight & $16(53.30 \%)$ & $24(60.00 \%)$ & $40(57.10 \%)$ & 0.577 \\
\hline $\begin{array}{l}\text { Left ventricular } \\
\text { ejection fraction }\end{array}$ & $55 \pm 10.29$ & $47.46 \pm 15.15$ & $50.73 \pm 13.70$ & 0.022 \\
\hline
\end{tabular}




\subsection{Impact of Rehabilitation}

\subsubsection{Parameters after Rehabilitation}

Exercise stress test was performed before rehabilitation for all 30 patients and after 6 months for 23 patients. For these 23 individuals, the functional capacity improved: $6.99 \pm 2.9$ Mets at M0 vs $8.8 \pm 2.23$ Mets at M6, $\mathrm{p}=0.0001$.

The BMI in the "rehabilitation" group decreased in six months: $25.35 \pm 4$ $\mathrm{kg} / \mathrm{m}^{2}$ to $24.53 \pm 3.71 \mathrm{~kg} / \mathrm{m}^{2}(\mathrm{p}=0.009)$ versus $25.66 \pm 3.20 \mathrm{~kg} / \mathrm{m}^{2}$ at $\mathrm{M} 0$ and $25.79 \pm 3.37 \mathrm{~kg} / \mathrm{m}^{2}$ at M6 $(\mathrm{p}=0.490)$ in control group. There was a significant increase of patients controlling waist circumference in the intervention group: $36.70 \%(\mathrm{n}=11)$ at $\mathrm{M} 0$ vs $63.33 \%(\mathrm{n}=19)$ at $\mathrm{M6}(\mathrm{p}=0.016)$.

Patients of the "rehabilitation" group globally significantly increased their motivation to get new healthy habits. They also improved their knowledge about their disease, their treatment, their diet and the physical activity which they could perform. Figure 1 shows the mean average of the intervention group for each item of the self-assessment questionnaire at baseline and after 6 months.

\subsubsection{Control of CVRF}

We found a significantly better control of CVRF factors in the intervention group. In this category, treatment compliance and regular practice of physical activity have also significantly improved from M0 to M6 (respectively $\mathrm{p}=$ $0.0001, \mathrm{p}=0.0001$ ) and comparatively to the control group after 6 months (respectively $\mathrm{p}=0.001, \mathrm{p}=0.0001)$. Table 2 summarizes the evolution of CVRF control, treatment in the two groups from the start (M0) to the end of the study at 6 months (M6).

At 6 months after program, 22 (73.30\%) individuals of "Rehabilitation group" reported a healthy diet vs $18(45.00 \%)$ of the controls $(\mathrm{p}=0.02)$.

\subsubsection{Outcomes in Ischemic Threshold, Return to Work and Sexual Activity}

We found in the "Rehabilitation group" an increase of clinical ischemic threshold in 27 subjects (90.00\%) after 3 months and in 29 subjects (96.70\%) after 6 months. In the controls, 35 individuals $(87.50 \%)$ reported an increase of ischemic threshold at 6-month follow-up ( $\mathrm{p}=0.18)$.

From the 41 employed people of our entire study population, only $8(19.50 \%)$ reported a temporary disability related to coronary artery disease. Three of them were in the intervention group and 05 in the control group. All these disabled patients at baseline returned to work at the 3-month follow-up.

At baseline, 01 man (3.33\%) in the case group and 01 man $(2.50 \%)$ in the control group reported an absence of sexual activity. At 6 months, any individual of the intervention group had this problem. But among the controls, 02 men stopped having sexual relationship with their partners. This fact was due to chest pain during sexual activity $(n=1)$ and the fear of cardiac arrest $(n=1)$.

In the intervention group, a psychosocial issue related to coronary artery disease was reported by $50.00 \%$ of individuals $(n=15)$ at M0, in $23.33 \%(n=07)$ at M3 $(\mathrm{p}=0.021)$, then in $30.00 \%(\mathrm{n}=09)$ at M6 $(\mathrm{p}=0.18)$. In the control group, 
this issue was found in $52.50 \%(\mathrm{n}=21)$ at M0 and $42.50 \%(\mathrm{n}=17)$ at M6 $(\mathrm{p}=$ $0.815)$.

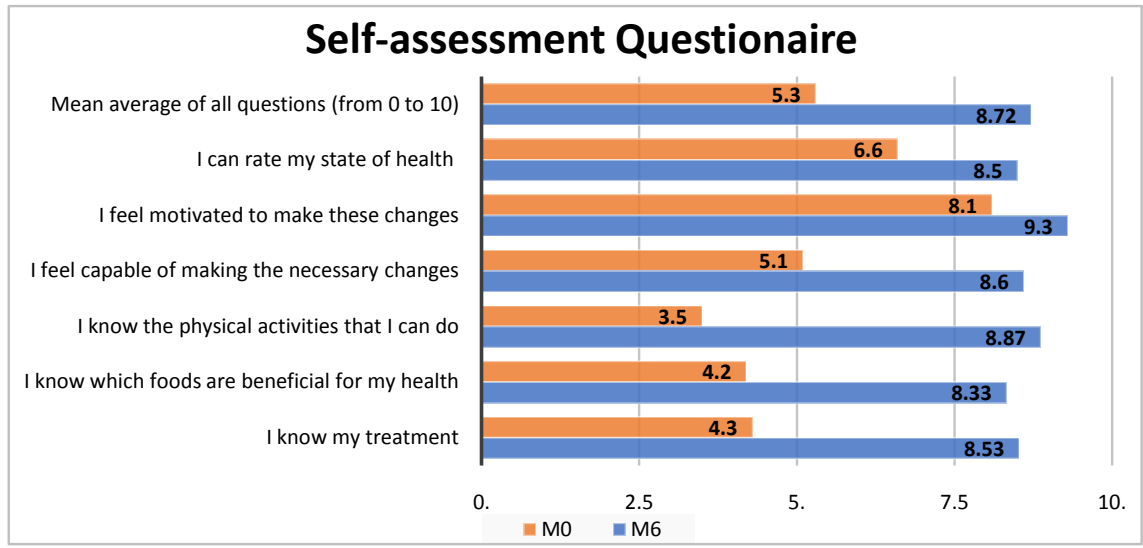

Figure 1. Mean average of the intervention group for each item of the self-assessment questionnaire at baseline and after 6 months.

Table 2. Evolution of cardiovascular risk factors control and therapeutic compliance between the two groups.

\begin{tabular}{|c|c|c|c|}
\hline & Rehabilitation & No rehabilitation & $\mathrm{p}^{\mathrm{a}}$ \\
\hline \multicolumn{4}{|c|}{ Hypertension control } \\
\hline M0 & $53.8 \%$ & $41.7 \%$ & 0.478 \\
\hline M6 & $84.6 \%$ & $33.3 \%$ & 0.003 \\
\hline $\mathrm{p}^{\mathrm{b}}$ & 0.125 & 0.174 & \\
\hline \multicolumn{4}{|c|}{ Diabetes control } \\
\hline M0 & $40.0 \%$ & $26.7 \%$ & 0.393 \\
\hline M6 & $70.0 \%$ & $26.7 \%$ & 0.042 \\
\hline $\mathrm{p}^{\mathrm{b}}$ & 0.375 & 0.999 & \\
\hline \multicolumn{4}{|c|}{ LDLc control } \\
\hline M0 & $26.67 \%$ & $10 \%$ & 0.067 \\
\hline M6 & $33.0 \%$ & $5.0 \%$ & 0.002 \\
\hline $\mathrm{p}^{\mathrm{b}}$ & 0.687 & 0.625 & \\
\hline \multicolumn{4}{|c|}{ Regular physical activity } \\
\hline M0 & $43.3 \%$ & $15.0 \%$ & 0.008 \\
\hline M6 & $93.3 \%$ & $37.5 \%$ & 0.0001 \\
\hline $\mathrm{p}^{\mathrm{b}}$ & 0.0001 & 0.064 & \\
\hline \multicolumn{4}{|c|}{ Complete treatment compliance } \\
\hline M0 & $26.6 \%$ & $30.0 \%$ & 0.76 \\
\hline M6 & $86.67 \%$ & $32.5 \%$ & 0.00001 \\
\hline $\mathrm{p}^{\mathrm{b}}$ & 0.0001 & 0.999 & \\
\hline
\end{tabular}

$\mathrm{p}^{\mathrm{a}}$ : $\mathrm{p}$ between Rehabilitation and no rehabilitation groups; $\mathrm{p}^{\mathrm{b}}$ : $\mathrm{p}$ between $\mathrm{M} 0$ and $\mathrm{M} 6$. 


\section{Discussion}

Cardiac rehabilitation cost-effectiveness has been widely proven around the world. But this intervention remains quasi inexistent in Africa, where several progresses have been made in the other fields of cardiovascular diseases management. Implementing the first Senegalese cardiac rehabilitation center was quite challenging due to many facts:

1) Lack of cardiorespiratory stress test equipment: we performed a simple exercise (treadmill) stress ECG without analysis of gas exchange. Therefore, we couldn't determine the ventilatory threshold and the exact initial intensity of exercise training.

2) We performed exercise training with programmable treadmills and ergometers for domestic use (medical use treadmills were expensive). We didn't have telemetry ECG; therefore, we only used a heart rate monitor chest strap.

3) Some medical insurance companies didn't recognize this activity and only patients who had enough financial support accepted to be enrolled.

4) For these same economic reasons, we had to reduce the number of training sessions to the minimum required for each patient to be independent and enough self-confident to continue regular physical activity.

5) Patient education should have considered our cultural context: talking about sexual activity in a mixed audience of elderly and young people is taboo subject, but it was well appreciated at the end of sessions.

Socio-demographic data such as age, gender, marital status and level of education, were not significantly different between the two groups. The practice of a professional activity and the existence of health insurance were significantly higher in the rehabilitation group ( $\mathrm{p} 0.05)$. This difference could be explained by the cost of the rehabilitation which reduced the accessibility of the program to patients who have a low socioeconomic level or are without financial support. These two parameters are themselves linked to the existence of a professional activity.

The age in the rehabilitation group was a bit younger than that reported by Pavy (63.4 \pm 10 years) [13] and by Adghar in Algeria (61 years) [6] in their series of coronary patients admitted to cardiac rehabilitation.

Our results show overall a remarkable improvement in the control of CVRF six months after the start of rehabilitation (Table 2).

Treatment compliance at inclusion in our series was low $30.00 \%$ in the rehabilitation group, $26.60 \%$ in the non-rehabilitation group). It is a challenge in the management of coronary artery disease. The most common non-compliance factors were forgetting to take medication and the high cost of medication in our cohort. These factors were also identified by Eagle as favoring non-compliance after ACS [14]. A positive impact of rehabilitation is suggested by our results. Peersen associated participation in a cardiovascular rehabilitation program with better treatment compliance $(\mathrm{RR}=2.32)$ [15]. This impact would be largely linked to patient education which leads to a better knowledge of the disease and 
the benefit of the treatment by the patient. In their study, Burke associated this better knowledge of the disease acquired in a cardiac rehabilitation program with better treatment compliance in the management of cardiovascular diseases [16].

Our data show improvement and maintenance of physical activity in the rehabilitated group 6 months after the program. A 2017 meta-analysis by Dibben found similar results, associating participation in a rehabilitation program with an increase in the level of physical activity [17]. An increase in the Ricci Gagnon score was noted at 6 months by Pavy [13] and 77\% of patients followed for 1 year by Denolle practiced physical activity regularly [18].

At baseline, even if difference may be apparent looking at percentages of diabetes control, $\mathrm{p}$ value was not significant at M0 between the two groups. The most relevant result is that at M6 and this might be due to better treatment adherence, low rate of sedentary lifestyle and improvement in diet found at M6 in the rehabilitated group. These results confirm those of EUROACTION [19] and Denolle [18], who found $73.00 \%$ of patients controlled at 1 year of the program.

Participation in the rehabilitation program was associated with an improvement in lipid balance with significantly higher LDL-C control in the group rehabilitation at $\mathrm{M} 6$ at $33.00 \%(\mathrm{p}=0.02)$ and a significant increase in the rate of HDL-C at M6 ( $\mathrm{p}=0.01$ ). These findings were similar to those of Denolle [18] and in EUROACTION [19] who respectively revealed $30.00 \%$ and $32.00 \%$ of LDLc control. It was better, by $76.00 \%$ in the Pavy series [13], due to a less severe therapeutic target, in accordance with the recommendations at the time of his survey (LDL less than $1 \mathrm{~g} / \mathrm{l}$ ).

Sexual dysfunction is a common issue among cardiac patients and can be predictive of future cardiovascular events and poorer quality of life [20]. Nearly half of these patients report a sexual problem, whether it is erectile dysfunction, lack of orgasm, or lack of interest [21] [22]. Age, male gender, BMI, hyperlipidemia, poor initial functional capacity are known to be independent factors of recovery of sexual activity [22] [23]. In our study, very few men confessed sexual dysfunction, probably because it is a taboo subject in our Senegalese culture. Women of our sample did not complain and some Senegalese series reveal their decency and resignation when it comes to sexual concerns [24]. Other reasons could be the size and the younger age of our sample, given that all the other factors (BMI, functional capacity, anxiety and depression) were quite similar to other studies. "Sexual life after coronary artery disease" is a component of our collective educational sessions available for all patients, as this is demonstrated by Lindau [25] be a significant predictor of resuming this activity.

Return to work is a major goal of cardiac rehabilitation, which improves health related quality of life, physical work capacity and resuming work [26] [27]. We found a little proportion of disabled patients at baseline and they all returned to work at 6-month follow-up. Female gender depression, limited secondary education, or low income are associated with decreased return to work 
rates after coronary artery bypass grafting surgery (CABG) [28] [29]. After a cardiac rehabilitation program following a CABG, persistent negative predictors to return to work are depression, age and negative subjective occupational prognosis [30]. The little size of our cohort did not allow us to do this analysis.

These psychosocial factors (symptoms of anxiety and/or depression) were reported by half of the intervention group at baseline but it decreased significantly at 3 then at 6 months. Assessment of psychosocial factor is very variable and some references suggest a better screening including vital exhaustion, type $\mathrm{D}$ personality, chronic stress at work, social support [31] [32]. However, our findings are consistent with those of Alqahtani who found that total distress, depression, anxiety, and hostility were reduced among patients who completed the CR programs [33]. Indeed, cardiac rehabilitation can help the patients to have better understanding of the influence of psychobiological risk factors and the way to manage their stress [34].

\section{Conclusion}

Our cardiac rehabilitation program in patients with coronary artery disease, resulted in good outcomes in a short period of time and with low cost equipment. It was efficient in controlling CVRF, reducing anxiety and depression symptoms, and improving treatment and diet compliance. Further investigations with larger population should be conducted to better assess the benefits of resuming sexual activity and returning to work.

\section{Conflicts of Interest}

The authors declare no conflicts of interest regarding the publication of this paper.

\section{References}

[1] World Health Organization (2019) Global Health Estimates 2016: Deaths by Cause, Age, Sex, by Country and by Region, 2000-2016. https://www.who.int/healthinfo/global burden disease/estimates/en/index1.html

[2] Rauch, B., Davos, C.H., Doherty, P., Saure, D., Metzendorf, M.-I., Salzwedel, A., et al. (2016) The Prognostic Effect of Cardiac Rehabilitation in the Era of Acute Revascularisation and Statin Therapy: A Systematic Review and Meta-Analysis of Randomized and Non-Randomized Studies-The Cardiac Rehabilitation Outcome Study (CROS). European Journal of Preventive Cardiology, 23, 1914-1939. https://doi.org/10.1177/2047487316671181

[3] Supervia, M., Turk-Adawi, K., Lopez-Jimenez, F., Pesah, E., Ding, R., Britto, R.R., et al. (2019) Nature of Cardiac Rehabilitation around the Globe. EClinicalMedicine, 13, 46-56. https://doi.org/10.1016/j.eclinm.2019.06.006

[4] Pesah, E., Supervia, M., Turk-Adawi, K. and Grace, S.L. (2017) A Review of Cardiac Rehabilitation Delivery around the World. Progress in Cardiovascular Diseases, 60, 267-280. https://doi.org/10.1016/j.pcad.2017.08.007

[5] Selim, G. (2013) Cardiac Rehabilitation in Egypt. Lancet Global Health, 1, e72. https://doi.org/10.1016/S2214-109X(13)70018-4 
[6] Adghar, D., Bougherbal, R., Hanifi, R. and Khellaf, N. (2008) Cardiac Rehabilitation: First Experience in Algeria. Annales de Cardiologie et d Angéiologie, 57, 44-47. https://doi.org/10.1016/j.ancard.2007.11.001

[7] Rengo, J.L., Savage, P.D., Barrett, T. and Ades, P.A. (2018) Participation Rates and Outcomes for Heart Failure Patients in Cardiac Rehabilitation. Journal of Cardiopulmonary Rehabilitation and Prevention, 38, 38-42. https://doi.org/10.1097/HCR.0000000000000252

[8] Turk-Adawi, K.I., Oldridge, N.B., Tarima, S.S., Stason, W.B. and Shepard, D.S. (2014) Cardiac Rehabilitation Enrollment among Referred Patients: Patient and Organizational Factors. Journal of Cardiopulmonary Rehabilitation and Prevention, 34, 114-122. https://doi.org/10.1097/HCR.0000000000000017

[9] Forhan, M., Zagorski, B.M., Marzonlini, S., Oh, P. and Alter, D.A. (2013) Predicting Exercise Adherence for Patients with Obesity and Diabetes Referred to a Cardiac Rehabilitation and Secondary Prevention Program. Canadian Journal of Diabetes, 37, 189-194. https://doi.org/10.1016/j.jcjd.2013.03.370

[10] Mykletun, A., Stordal, E. and Dahl, A.A. (2001) Hospital Anxiety and Depression (HAD) Scale: Factor Structure, Item Analyses and Internal Consistency in a Large Population. British Journal of Psychiatry, 179, 540-544.

https://doi.org/10.1192/bjp.179.6.540

[11] Piepoli, M.F., Hoes, A.W., Agewall, S., Albus, C., Brotons, C., Catapano, A.L., et al. (2016) 2016 European Guidelines on Cardiovascular Disease Prevention in Clinical Practice: The Sixth Joint Task Force of the European Society of Cardiology and Other Societies on Cardiovascular Disease Prevention in Clinical Practice (Constituted by Representatives of 10 Societies and by Invited Experts) Developed with the Special Contribution of the European Association for Cardiovascular Prevention \& Rehabilitation (EACPR). European Heart Journal, 37, 2315-2381. https://doi.org/10.1093/eurheartj/ehw106

[12] Girerd, X., Radauceanu, A., Achard, J.M., Fourcade, J., Tournier, B., Brillet, G., et al. (2001) Evaluation of Patient Compliance among Hypertensive Patients Treated by Specialists. Archives des Maladies du Coeur et des Vaisseaux, 94, 839-842.

[13] Pavy, B., Tisseau, A. and Caillon, M. (2011) Le patient coronarien six mois après la réadaptation cardiaque: Recherche sur l'évaluation de la réadaptation (étude RER). Annales de Cardiologie et d'Angéiologie, 60, 252-258. https://doi.org/10.1016/j.ancard.2011.08.004

[14] Eagle, K.A., Kline-Rogers, E., Goodman, S.G., Gurfinkel, E.P., Avezum, A., Flather, M.D., et al. (2004) Adherence to Evidence-Based Therapies after Discharge for Acute Coronary Syndromes: An Ongoing Prospective, Observational Study. American Journal of Medicine, 117, 73-81. https://doi.org/10.1016/j.amjmed.2003.12.041

[15] Peersen, K., Munkhaugen, J., Gullestad, L., Liodden, T., Moum, T., Dammen, T., et al. (2017) The Role of Cardiac Rehabilitation in Secondary Prevention after Coronary Events. European Journal of Preventive Cardiology, 24, 1360-1368. https://doi.org/10.1177/2047487317719355

[16] Burke, L.E., Dunbar-Jacob, J.M. and Hill, M.N. (1997) Compliance with Cardiovascular Disease Prevention Strategies: A Review of the Research. Annals of Behavioral Medicine, 19, 239-263. https://doi.org/10.1007/BF02892289

[17] Dibben, G.O., Dalal, H.M., Taylor, R.S., Doherty, P., Tang, L.H. and Hillsdon, M. (2018) Cardiac Rehabilitation and Physical Activity: Systematic Review and Meta-Analysis. Heart, 104, 1394-1402. https://doi.org/10.1136/heartjnl-2017-312832

[18] Denolle, T., Dib, M., Brune, M., Nicolas, S., Richard, A., Auguste, V., et al. (2017) 
Control of Cardiovascular Risk Factors in Coronary Patients One Year after Cardiac Rehabilitation. Annales de Cardiologie et d Angéiologie, 66, 135-139. https://doi.org/10.1016/j.ancard.2017.04.005

[19] Wood, D., Kotseva, K., Connolly, S., Jennings, C., Mead, A., Jones, J., et al. (2008) Nurse-Coordinated Multidisciplinary, Family-Based Cardiovascular Disease Prevention Programme (EUROACTION) for Patients with Coronary Heart Disease and Asymptomatic Individuals at High Risk of Cardiovascular Disease: A Paired, Cluster-Randomised Controlled Trial. Lancet, 371, 1999-2012.

https://doi.org/10.1016/S0140-6736(08)60868-5

[20] Mornar Jelavić, M., Krstačić, G., Perenčević, A. and Pintarić, H. (2018) Sexual Activity in Patients with Cardiac Diseases. Acta clinica Croatica, 57, 141-148. https://doi.org/10.20471/acc.2018.57.01.18

[21] Byrne, M., Doherty, S., Murphy, A.W., McGee, H.M. and Jaarsma, T. (2013) The CHARMS Study: Cardiac Patients' Experiences of Sexual Problems Following Cardiac Rehabilitation. European Journal of Cardiovascular Nursing, 12, 558-566. https://doi.org/10.1177/1474515113477273

[22] Schumann, J., Zellweger, M.J., Di Valentino, M., Piazzalunga, S. and Hoffmann, A. (2010) Sexual Dysfunction before and after Cardiac Rehabilitation. Rehabilitation Research and Practice, 2010, Article ID: 823060. https://doi.org/10.1155/2010/823060

[23] Lim, S.K., Sim, D.S. and Han, J.Y. (2016) The Factors Associated with Sexual Recovery in Male Patients with Acute Myocardial Infarction under Phase II Cardiac Rehabilitation. Journal of Clinical Nursing, 25, 2827-2834. https://doi.org/10.1111/jocn.13324

[24] Diouf, A.A., Diallo, D., Niang, P.Y., Niass, A., Koulimaya-Gombet, C.E., Diallo, M., et al. (2019) Sexualité des femmes ménopausées en Afrique sub-saharienne: Exemple du Sénégal [Sexuality in Postmenopausal Women in Sub-Saharan Africa: Example from Senegal]. Pan African Medical Journal, 32, Article No. 1. https://doi.org/10.11604/pamj.2019.32.1.17755

[25] Lindau, S.T., Abramsohn, E., Gosch, K., Wroblewski, K., Spatz, E.S., Chan, P.S., et al. (2012) Patterns and Loss of Sexual Activity in the Year Following Hospitalization for Acute Myocardial Infarction-A United States National Multisite Observational Study. American Journal of Cardiology, 109, 1439-1444. https://doi.org/10.1016/j.amjcard.2012.01.355

[26] Simchen, E., Naveh, I., Zitser-Gurevich, Y., Brown, D. and Galai, N. (2001) Is Participation in Cardiac Rehabilitation Programs Associated with Better Quality of Life and Return to Work after Coronary Artery Bypass Operations? The Israeli CABG Study. Israel Medical Association Journal, 3, 399-403.

[27] Perk, J., Hedback, B. and Engvall, J. (1990) Effects of Cardiac Rehabilitation after Coronary Artery Bypass Grafting on Readmissions, Return to Work, and Physical Fitness. A Case-Control Study. Scandinavian Journal of Public Health, 18, 45-51. https://doi.org/10.1177\%2F140349489001800107

[28] Söderman, E., Lisspers, J. and Sundin, O. (2003) Depression as a Predictor of Return to Work in Patients with Coronary Artery Disease. Social Science \& Medicine, 56, 193-202. https://doi.org/10.1016/S0277-9536(02)00024-2

[29] Mortensen, M., Sandvik, R.K.N.M., Svendsen, Ø.S., Haaverstad, R. and Moi, A.L. (2021) Return to Work after Coronary Artery Bypass Grafting and Aortic Valve Replacement Surgery: A Scoping Review. Scandinavian Journal of Caring Sciences. https://doi.org/10.1111/scs.13006 
[30] Salzwedel, A., Reibis, R., Heidler, M.D., Wegscheider, K. and Völler, H. (2019) Determinants of Return to Work after Multicomponent Cardiac Rehabilitation. Archives of Physical Medicine and Rehabilitation, 100, 2399-2402. https://doi.org/10.1016/j.apmr.2019.04.003

[31] Mesa-Vieira, C., Grolimund, J., von Känel, R., Franco, O.H. and Saner, H. (2021) Psychosocial Risk Factors in Cardiac Rehabilitation: Time to Screen beyond Anxiety and Depression. Glob Heart, 16, 16. http://doi.org/10.5334/gh.896

[32] Perk, J., De Backer, G., Gohlke, H., Graham, I., Reiner, Z. and Verschuren, M. (2012) European Guidelines on Cardiovascular Disease Prevention in Clinical Practice (Version 2012). European Heart Journal, 33, 1635-1671. https://doi.org/10.1093/eurheartj/ehs092

[33] Alqahtani, M., Alanazi, A.M.M., Yohannes, A.M., Smith, C.E. and Goodfellow, L.T. (2021) The Effectiveness of Cardiopulmonary Rehabilitation Programs on Psychosocial Factors in Patients with Pulmonary and Cardiac Disease. Journal of Cardiopulmonary Rehabilitation and Prevention, 41, 271-276. https://doi.org/10.1097/HCR.0000000000000599

[34] Chauvet-Gelinier, J.C. and Bonin, B. (2017) Stress, Anxiety and Depression in Heart Disease Patients: A Major Challenge for Cardiac Rehabilitation. Annals of Physical and Rehabilitation Medicine, 60, 6-12. https://doi.org/10.1016/j.rehab.2016.09.002

\section{List of Abbreviations}

WHO: World Health Organization

CVRF: Cardiovascular Risk Factors

BP: Blood Pressure

HR: Heart Rate

HDL: High Density Lipoprotein

LDL: Low Density Lipoprotein

ESC: European Society of Cardiology

ACS: Acute Coronary Syndrome

CCS: Chronic Coronary Syndrome

BMI: Body Mass Index 